\title{
DISTRIBUCIÓN TEMPORAL DE SÍNTOMAS DEL AMARILLAMIENTO DE LA HOJA EN LA CAÑA DE AZÚCAR EN CUBA $^{1}$
}

\author{
Osmany de la Caridad Aday-Díaz², José María Mesa-López, María de La O-Hechavarría ${ }^{3}$, Félix René Díaz- \\ Mujica $^{2}$, Irenaldo Delgado-Mora ${ }^{2}$, Mayelin Morales-Sarmiento ${ }^{4}$
}

\begin{abstract}
RESUMEN
Distribución temporal de síntomas del amarillamiento de la hoja en la caña de azúcar en Cuba. El objetivo del presente estudio fue determinar la distribución temporal de los síntomas fisiológicos de la enfermedad amarillamiento de la hoja (SCYP) y su relación con las variables climáticas en la región central de Cuba. Las evaluaciones mensuales de campo se efectuaron en tres experimentos ubicados en dos localidades, durante el período del 2003 al 2007 desde el comienzo de los primeros síntomas. Con un refractómetro de mano se registraron los valores de brix refractométrico del tercio basal de la tercera hoja con cuello visible (TVD). Se determinaron las correlaciones de los valores de Brix observados con las variables climáticas. Los primeros síntomas del amarillamiento de la hoja, aparecieron en plantas de cinco meses de edad, independientemente de la época de plantación, se manifestaron con el inicio de la estación invernal y disminuyeron con el inicio de la primavera. El brix de la hoja se incrementó desde noviembre y alcanzó un máximo en el mes de abril, posteriormente las plantas se tornaron asintomáticas. La disminución de las temperaturas máximas, mínimas y medias inferiores a 30,21 y $25^{\circ} \mathrm{C}$, respectivamente, así como precipitaciones mensuales inferiores a $50 \mathrm{~mm}$, favorecieron la expresión de los síntomas; ellos estuvieron más relacionadas con el clima que con la edad del cultivo, en coincidencia con el período seco de maduración y cosecha de la caña.
\end{abstract}

Palabras claves: Síndrome de la hoja amarilla, variables climáticas, fitoplasma, Brix.

\begin{abstract}
Temporary distribution of symptoms of the sugarcane leaf yellowing in Cuba. The objective of this study was to determine the temporal distribution of the physiological symptoms of leaf yellowing disease of sugarcane and its relationship with weather variables in the central region of Cuba. Field evaluations were conducted in three experiments in two locations, during the period from 2003 to 2007. Monthly evaluations were carried out starting with the appearence of the first symptoms, using a hand refractometer to record values of refractometric brix of the basal third of the third leaf with visible dewlap (TVD). Correlations of the values of observed brix were with climatic variables were obtained. The first symptoms of leaf yellowing appeared in plants of five months of age, independently of the time of sowing, at the beginning of the winter season, and then decreased with the beginning of the spring. The brix of the leaf increased from November and reached a maximum in April, after which the plants became asymptomatic. The decrease of the maximum, minimum and monthly average temperatures below 30,21 and $25^{\circ} \mathrm{C}$, respectively, as well as monthly precipitations lower than 50 $\mathrm{mm}$, favored the expression of the symptoms, which were more related to climate than to crop age, in coincidence with the dry period of maturation and harvesting time of sugarcane.
\end{abstract}

Key words: Leaf yellowing syndrome, climatic variables, phytoplasma, Brix.

\footnotetext{
1 Recibido: 4 de julio, 2011. Aceptado: 12 de marzo, 2012. Proyecto Nacional CITMA, Cuba: Obtención, selección y manejo de genotipos de caña de azúcar, resistentes a las principales enfermedades. Código: 101214.

2 Estación Territorial de Investigaciones de la Caña de Azúcar Villa Clara - Cienfuegos. Autopista Nacional, Km 246, Ranchuelo; Villa Clara, Cuba,CP53100.epica@vcl.cu; director@epica.vc.minaz.cu; fitomejoramiento@epica.vc.minaz.cu

3 Instituto Nacional de Investigaciones de la Caña de Azúcar, Carretera al Central Martínez Prieto Km 2 1/2, Boyeros, CP19390, Ciudad de la Habana,Cuba.mesa@inica.minaz.cu; lao@inica.minaz.cu.

4 Delegación Provincial del CITMA, Candelaria No. 6 entre Cuba y Colón Santa Clara, Villa Clara, Cuba, CP50100. directora@dcitma.vcl.cu
} 


\section{INTRODUCCIÓN}

En Hawaii, se informó por primera vez en 1988 una nueva enfermedad de la caña de azúcar, la cual fue denominada entonces síndrome de la hoja amarilla de la caña de azúcar (Yellow Leaf Syndrome, YLS) (Schenck 1990, Schenck y Hu 1991). Este síndrome se ha expandido muy rápido, siendo reportado ya en más de 35 países (Lockhart y Cronjé, 2000) y este número todavía sigue en aumento (Ávila et al. 2001, Garcés et al. 2005).

Los resultados de los estudios realizados anteriormente en Cuba sobre el YLS (Peralta et al. 1999), describen los síntomas que presenta la enfermedad: coloración amarilla del raquis por el envés de la hoja que se abre hacia los limbos foliares y amarillento generalizado del follaje, muchas veces acompañado por necrosis, en algunos cultivares se presenta coloración violácea de la nervadura por el haz, que también puede abrirse hacia los limbos brix refractométrico de las hojas de plantas enfermas generalmente dos o tres veces superiores al de las hojas sanas, afectaciones del sistema radical en forma de necrosis parcial o total de las raíces, destrucción de los pelos absorbentes, raicillas, raíces secundarias y primarias.

Dos patógenos están asociados a los síntomas del YLS, un virus y un fitoplasma (Rott et al. 2008), los síntomas causados por ambos patógenos son idénticos (Smith et al. 2001). Para diferenciarlas el Comité para los Nombres Comunes de Enfermedades de las plantas de la Sociedad Internacional de Patólogos de Plantas (ISPP) sugirió nombrar "la hoja amarilla" a la ocasionada por el virus SCYLV, y "amarillamiento de la hoja”, a la causada por el fitoplasma SCYP, esta sugerencia fue aceptada por el Comité de Patología de la Sociedad Internacional de Tecnólogos de la Caña de Azúcar (ISSCT) en su Sétimo Taller, sostenido en Baton Rouge, Louisiana, en el 2003 (Rott et al. 2005).

En Cuba, en evaluaciones realizadas en Jovellanos, provincia de Matanzas, solo un pequeño porcentaje de caña presentó el virus, el diagnóstico por PCR determinó la asociación de la enfermedad con el grupo fitoplasmático amarillamiento del áster (AY), subgrupo I-A (Arocha et al. 1999).

El SCYLP es asociado a un incremento de la concentración de azúcares reductores, índice de glucosa y glicoproteínas recuperadas en jugo, mientras que decrece el contenido de sacarosa. La enfermedad es asociada a un incremento de la fracción total de poliaminas. La actividad de Arginasa y Ornitine carboxilasa, resulta ser alta en el jugo de plantas enfermas con SCYP en comparación con lo obtenidos de plantas sanas (Fontaniella et al. 2003).

Se ha demostrado que ambos patógenos (SCYLV Y SCYP), se transmiten por trozos de semilla agámica y pueden ser eliminados de las plantas infectadas, mediante cultivo de callos de las hojas más jóvenes que envuelven el ápice meristemático (Parmessur et al. 2002). Bajo determinadas condiciones ambientales, ambas enfermedades pueden estar de forma intermitente o asintomática. Para establecer medidas de control oportunas, constituye un problema a resolver en cada país, ya que se dificultó determinar el momento oportuno para evaluar la enfermedad, este parece estar muy relacionado con la edad y condiciones climáticas.

Probablemente la aparición temprana del amarillamiento de la hoja (SCYP), depende de varios factores tales como: la calidad fitosanitaria de la semilla (si no está infestada), susceptibilidad de los cultivares, influencia ambiental o interacción ambiente- patógenocultivar (Arocha et al. 2000).

Este trabajo tuvo como objetivo determinar la distribución temporal de los síntomas de la enfermedad y su relación con las variables climáticas de mayor importancia en la región central de Cuba.

\section{MATERIALES Y MÉTODOS}

\section{Experimentos}

Las evaluaciones de campo se desarrollaron en tres experimentos, en dos localidades. Dos fueron realizados en una zona de alta incidencia del amarillamiento de la hoja (SCYP), en áreas de la unidad productora de caña de azúcar "Alegría", de la Empresa Azucarera "14 de Julio", municipio Cienfuegos, provincia de Cienfuegos, durante el período 2003-2006. El tercer experimento se llevó a cabo en el área experimental de la Estación Territorial de Investigaciones de la Caña de Azúcar (ETICA) de Villa Clara, durante el período del 2004 al 2007. provincia Villa Clara, durante el período del 2004 al 2007. Todos plantados en suelo Pardo Sialítico Cálcico (Hernández et al. 1999) [Calcic Haplustept (Soil Survey Staff 2003)]. 


\section{Diseño y atención de experimentos}

El diseño experimental empleado fue el de bloques al azar, con parcelas de cuatro surcos de seis metros de largo $\left(38,4 \mathrm{~m}^{2}\right)$ y tres réplicas. Cada una contó con catorce parcelas (una por cada variedad en estudio).

En cada experimento se ubicaron hileras de borde laterales (un surco) con el cultivar C1051-73 y una franja de un metro en la parte anterior y posterior también con esta variedad, además fueron ubicadas hileras de infección entre cada parcela con los cultivares C1051-73 y C120-78. En la plantación de estas variedades se empleó semilla agámica enferma procedente de áreas infestadas por SCYP. La semilla empleada en la plantación de las parcelas a evaluar, procedió del Banco de Semilla Básica de la ETICA en Villa Clara, Cuba.

Experimento No. 1. Fecha de plantación: Julio, 2003 (Plantación de Ciclo Largo de Primavera, de veintiún meses). Catorce variedades: C120-78; C1051-73; C87-51; C132-81; C85-102; C86-12; C86156; C86-165; C86-503; C89-161; C90-530; C90-501; Co997; SP70-1284.

Experimento No. 2. Fecha de plantación: Septiembre, 2003. (Plantación de Ciclo de Frío, de dieciocho meses). Catorce variedades: de ellos se repiten diez que fueron plantados en el Experimento de Primavera. C120-78; C1051-73; C87-51; C323-68; C13781; C85-102; C86-12; C86-156; C86-503; C89-148; C89-161; C89-250; C90-530; SP70-1284.

Experimento No. 3. Fecha de plantación: Julio, 2004 (Plantación de Ciclo Largo de Primavera, de veintiún meses). Diez variedades: C120-78; C105173; C132-81; C86-165; Co997; SP70-1284; C85-102; C86-12; C90-501; C90-530.

La fertilización se realizó conforme al Servicio de Recomendaciones de Fertilizantes y Enmiendas (SERFE) del Instituto Nacional de Investigaciones de la Caña de Azúcar (INICA), el control de malezas se realizó de forma manual y mecanizada por labores de cultivo y acondicionamiento, no se emplearon químicos, la cosecha se realizó con máquinas cosechadoras.

\section{Diagnóstico de la enfermedad}

En el Experimento No. 3, en el mes de marzo del 2007, se colectaron 66 muestras de hojas de 22 plantas de once variedades (C120-78; C1051-73; C132-81; C86-165; Co997; SP70-1284; C85-102; C86-12; C90501; C90-530), todas con síntomas de amarillamiento de la hoja. Las plantas evaluadas tenían una edad de doce meses, en ciclo de primer retoño (soca). Se colectaron las hojas $+2,+3$ y +4 , de dos tallos con síntomas de la enfermedad, de cada una de las variedades. Se tomaron $200 \mathrm{mg}$ de la lámina de la hoja, se maceraron en nitrógeno líquido y se procedió a extraer el ADN utilizando el juego RNeasy ${ }^{\circledR}$ Plant Mini Kit. Posteriormente, se realizó la Reacción en Cadena de la Polimerasa anidada (nPCR) y la digestión enzimática con la enzima de restricción HaeIII según indicaciones de Cronjé et al. (1998). El ADN total de las muestras foliares colectadas de las tres variedades, fue analizado mediante nPCR con iniciadores genéricos que amplifican la región del ARN ribosomal 16S de fitoplasmas, así como análisis de restricción con la enzima HaeIII.

\section{Evaluaciones}

En cada experimento, en cepas de caña planta y retoño, fueron realizadas evaluaciones mensuales desde el comienzo de los primeros síntomas de amarillamiento de la hoja. Mediante un refractómetro de mano se registró el valor de brix refractométrico del tercio basal de la tercera hoja con cuello visible (TVD: top visible dewlap), hasta obtener cuatro observaciones de cada parcela por réplica y un total de doce por variedad. De acuerdo con el método propuesto por Arocha et al. (2000), para la detección en campo de esta enfermedad, se consideraron positivas las muestras con síntomas y valores de brix iguales o superiores a ocho.

Para el estudio de la influencia del clima en el desarrollo de la expresión de los síntomas de la enfermedad, fue utilizada la información climática de los Centros Meteorológicos Provinciales de Cienfuegos y Villa Clara (temperatura, evaporación y humedad relativa) y los registros de precipitaciones de los pluviómetros ubicados en los sitios donde se realizaron los estudios. Con esta información y el valor medio mensual del máximo valor de brix refractométrico de todos los cultivares, fueron confeccionadas dos bases de datos.

\section{Procesamiento de la información y análisis esta- dísticos}

Se realizaron análisis de varianza simple para comparar las dos localidades donde se desarrollaron 
los estudios; Análisis de Componentes Principales y correlación de factores, para determinar las variables de mayor correlación con el brix de la hoja, en las cepas de caña planta y en retoño; finalmente se determinaron las correlaciones entre las variables de mayor importancia con el brix de la hoja, en cada cepa. Fueron empleados los programas estadísticos STATISTICA Versión 6,1 y STAGRAPHICS PLUS Versión 4.1.

\section{RESULTADOS Y DISCUSIÓN}

De las 66 muestras de hojas evaluadas procedentes de veintidós plantas de las once variedades sometidas a diagnóstico por Nested-PCR (tres muestras de hoja por planta; dos plantas por variedad), en las once variedades con síntomas se detectó SCYP. Todas las plantas evaluadas con síntomas, excepto una de C90530 y una de C86-156, resultaron positivas a SCYP; de las 57 hojas analizadas con síntomas de amarillamiento y brix mayor de ocho, resultaron positivas 47 $(82,46 \%)$ (Cuadro 1). Estos resultados coinciden con

Cuadro 1. Diagnóstico de laboratorio por reacción en cadena de la polimeraza anidada (nPCR), en las muestras de once variedades de caña de azúcar bajo incidencia del amarillamiento de la hoja (SYCP) procedentes de Villa Clara, Cuba. 2007.

\begin{tabular}{lcccc}
\hline Variedad & Tallo & No hoja & $\begin{array}{c}\text { Brix de } \\
\text { la hoja }\end{array}$ & SCYP \\
\hline \multirow{4}{*}{ C1051-73 } & 1 & +2 & 12,8 & - \\
& 1 & +3 & 9,8 & + \\
& 1 & +4 & 9,6 & + \\
& 2 & +4 & 9,6 & - \\
& 2 & +3 & 5,6 & + \\
& 2 & +2 & 5,4 & + \\
\hline \multirow{4}{*}{ 120-78 } & 1 & +2 & 8,8 & + \\
& 1 & +3 & 8,0 & + \\
& 1 & +4 & 7,0 & + \\
& 2 & +2 & 14,6 & - \\
& 2 & +3 & 10,0 & + \\
& 2 & +4 & 10,0 & + \\
\hline \multirow{5}{*}{$132-81$} & 1 & +2 & 11,4 & + \\
& 1 & +3 & 10,4 & + \\
& 1 & +4 & 9,2 & + \\
& 2 & +2 & 10,0 & + \\
& 2 & +3 & 9,0 & + \\
& 2 & +4 & 8,6 & + \\
\hline
\end{tabular}

Continúa...
Continuación Cuadro 1...

\begin{tabular}{|c|c|c|c|c|}
\hline \multirow{6}{*}{ C $86-12$} & 1 & +2 & 9,6 & + \\
\hline & 1 & +3 & 8,0 & + \\
\hline & 1 & +4 & 6,6 & + \\
\hline & 2 & +2 & 9,4 & + \\
\hline & 2 & +3 & 9,6 & + \\
\hline & 2 & +4 & 6,6 & + \\
\hline \multirow{6}{*}{ C85-102 } & 1 & +2 & 12,0 & + \\
\hline & 1 & +3 & 12,0 & + \\
\hline & 1 & +4 & 9,6 & - \\
\hline & 2 & +2 & 12,0 & + \\
\hline & 2 & +3 & 12,6 & + \\
\hline & 2 & +4 & 8,6 & + \\
\hline \multirow{6}{*}{ C86-156 } & 1 & +2 & 16,0 & + \\
\hline & 1 & +3 & 15,4 & - \\
\hline & 1 & +4 & 12,6 & - \\
\hline & 2 & +2 & 15,6 & - \\
\hline & 2 & +3 & 13,4 & + \\
\hline & 2 & +4 & 12,2 & + \\
\hline \multirow{6}{*}{ C $86-165$} & 1 & +2 & 15,4 & + \\
\hline & 1 & +3 & 12,4 & + \\
\hline & 1 & +4 & 8,2 & + \\
\hline & 2 & +2 & 16,6 & + \\
\hline & 2 & +3 & 14,4 & + \\
\hline & 2 & +4 & 13,2 & - \\
\hline \multirow{6}{*}{ C90-501 } & 2 & +2 & 10,6 & + \\
\hline & 2 & +3 & 9,6 & + \\
\hline & 2 & +4 & 7,6 & + \\
\hline & 1 & +2 & 13,0 & + \\
\hline & 1 & +3 & 11,0 & + \\
\hline & 1 & +4 & 11,0 & + \\
\hline \multirow{6}{*}{ C 90-530 } & 1 & +2 & 17,0 & - \\
\hline & 1 & +3 & 16,0 & - \\
\hline & 1 & +4 & 14,0 & - \\
\hline & 2 & +2 & 16,2 & + \\
\hline & 2 & +3 & 14,0 & + \\
\hline & 2 & +4 & 13,2 & + \\
\hline \multirow{6}{*}{ Co 997} & 1 & +2 & 8,4 & + \\
\hline & 1 & +3 & 11,6 & + \\
\hline & 1 & +4 & 9,0 & + \\
\hline & 2 & +2 & 10,6 & + \\
\hline & 2 & +3 & 10,4 & + \\
\hline & 2 & +4 & 11,4 & - \\
\hline \multirow{6}{*}{ SP70-1284 } & 1 & +2 & 9,6 & + \\
\hline & 1 & +3 & 9,4 & + \\
\hline & 1 & +4 & 5,4 & + \\
\hline & 2 & +2 & 6,8 & - \\
\hline & 2 & +3 & 6,6 & - \\
\hline & 2 & +4 & 7,4 & + \\
\hline
\end{tabular}

AGRONOMÍA MESOAMERICANA 23(1):107-116. 2012 
los obtenidos en Cuba por Arocha et al. (2004; 2005; 2006).

La distribución de síntomas fisiológicos del amarillamiento de la hoja en el tiempo "caña planta", se muestra en la Figura 1. En los experimentos No. 1 y No. 3 (Plantación de Ciclo Largo de Primavera) en las localidades de Cienfuegos y Villa Clara, los primeros síntomas del amarillamiento de la hoja se registraron en el mes de noviembre, a los cinco meses después de la plantación; en el experimento No. 2 (Plantación de Ciclo de Frío), en la localidad de Cienfuegos, los primeros síntomas se observaron en el mes de marzo, a los seis meses posteriores a la plantación.

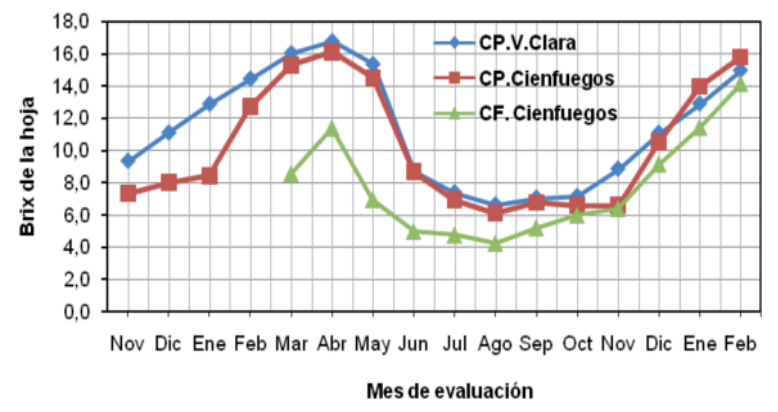

Figura 1. Distribución en el tiempo de los síntomas del amarillamiento de la hoja (SCYP) en caña planta, en caña de azúcar expresada en el brix refractométrico de la hoja. Cienfuegos 2003-2005 y Villa Clara 2004-2006, Cuba.

CP: Ciclo Primavera; CF: Ciclo de Frío.

En la cepa de "retoño", también llamada "soca", en los tres experimentos y en las dos localidades de estudio, los síntomas de la enfermedad comenzaron a manifestarse en el mes de noviembre, cuando las plantas tenían nueve meses de edad (Figura 2). Los resultados obtenidos en este estudio coinciden con los publicados por Cronjé et al. (1996), ellos señalaron que los síntomas del amarillamiento de la hoja aparecen típicamente en muestras foliares de caña de azúcar de seis meses o más. En Cuba, Arocha et al. (2000), observó la presencia del amarillamiento de la hoja en todas las edades de la planta, con una mayor incidencia en el período de trece a veintidós meses de edad o más.

En todos los experimentos, localidades y ciclos de plantación, "caña planta" y "retoño", se observaron los síntomas de la enfermedad y específicamente altos

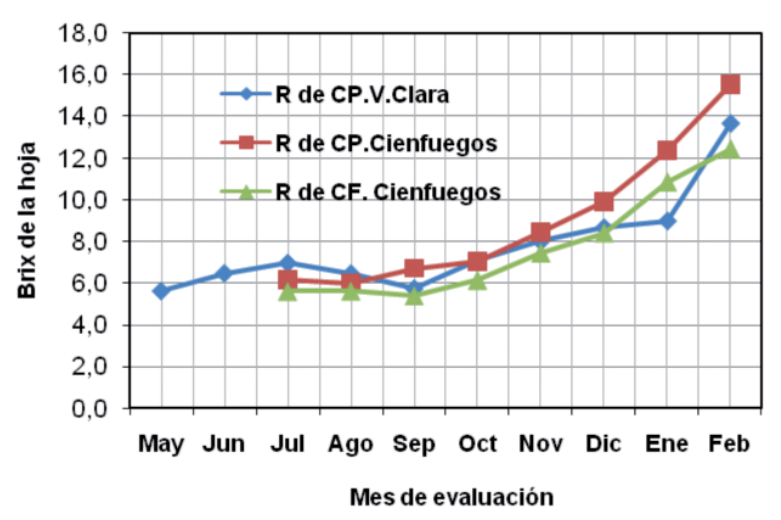

Figura 2. Distribución en el tiempo de los síntomas del amarillamiento de la hoja (SCYP) en retoño, en caña de azúcar expresada en el brix refractométrico de la hoja. Cienfuegos 2005-2006 y Villa Clara 20062007, Cuba.

CP: Ciclo Primavera; CF: Ciclo de Frío.

valores del brix de la hoja, desde el mes de noviembre y su progresivo incremento hasta alcanzar un máximo entre marzo y abril, luego disminuyen y prácticamente desaparecen en el mes de julio (Figura 1 y 2). Los resultados muestran que la distribución de los síntomas del amarillamiento de la hoja en el tiempo, se manifestaron con el inicio de la estación invernal y disminuyeron con de la primavera, desapareciendo completamente durante el verano.

Resultados similares a los obtenidos en este estudio fueron obtenidos por Bailey et al. (1996), cuando se refieren a que los síntomas de esta enfermedad ocurren en todas las épocas del año, y en cañas de todas las edades, en dependencia del cultivar, pero sus experiencias en Sudáfrica han indicado que estas son más frecuentemente observadas en caña madura durante los meses más secos y fríos del invierno y la primavera. También Schenck et al. (1997) y Comstock et al. (1998), observaron en E.U.A. y Hawai, respectivamente, que los síntomas de la enfermedad de la hoja amarilla (virus SCYLV) son más evidentes en plantas de cañas maduras.

El análisis de varianza simple (Cuadro 2), mostró que no existieron diferencias significativas entre las dos localidades donde se desarrollaron los experimentos, en cuanto a las temperaturas, precipitaciones, la edad de las plantaciones y el brix de la hoja observado. Ambas localidades difieren entre sí en cuanto a humedad relativa y evaporación, la primera variable fue mayor 
Cuadro 2. Comparación de las medias de las variables climáticas en dos localidades 1 Cienfuegos y 2 Villa Clara, Cuba, donde se evaluó el amarillamiento de la hoja de la caña de azúcar (SCYP). Villa Clara, Cuba. 2007.

\begin{tabular}{lcccccccc}
\hline & \multicolumn{7}{c}{ Medias de las variables climáticas } \\
\cline { 2 - 9 } Localidades & $\begin{array}{c}\text { Temperatura } \\
\text { máxima }\end{array}$ & $\begin{array}{c}\text { Temperatura } \\
\text { mínima }\end{array}$ & $\begin{array}{c}\text { Temperatura } \\
\text { media }\end{array}$ & $\begin{array}{c}\text { Humedad } \\
\text { relativa }\end{array}$ & Evaporación & Precipitación & $\begin{array}{c}\text { Edad } \\
\text { Brix de } \\
\text { la hoja }\end{array}$ \\
\hline Cienfuegos & $30,57 \mathrm{a}$ & $19,98 \mathrm{a}$ & $24,47 \mathrm{a}$ & $74,57 \mathrm{~b}$ & $188,5 \mathrm{a}$ & $56,44 \mathrm{a}$ & $325,1 \mathrm{a}$ & $9,2 \mathrm{a}$ \\
Villa Clara & $30,64 \mathrm{a}$ & $19,03 \mathrm{a}$ & $24,07 \mathrm{a}$ & $77,58 \mathrm{a}$ & $150,3 \mathrm{~b}$ & $110,20 \mathrm{a}$ & $335,8 \mathrm{a}$ & $9,9 \mathrm{a}$ \\
Valor de P. & 0,8946 & 0,1848 & 0,4527 & 0,0443 & 0,0001 & 0,0615 & 0,7573 & 0,4219 \\
\hline
\end{tabular}

Valores con letras no comunes en una misma columna difieren estadísticamente entre sí por el Método Tukey HSD: 95,0\%.

69 observaciones.

en Villa Clara y la segunda lo fue en Cienfuegos; sin embargo estas diferencias no son suficientemente contrastantes, por ello se considera que las condiciones climáticas durante el tiempo en que se desarrolló de los estudios fueron similares en las dos localidades y estas constituyen réplicas experimentales.

Se realizó un primer análisis de componentes principales, de los datos obtenidos en caña planta de los tres experimentos (Ciclo de Primavera Cienfuegos, Ciclo de Primavera Villa Clara y Ciclo de Frío Cienfuegos), (Cuadro 3). Dos componentes explicaron el $71,74 \%$ del total de la varianza y fue más importante el primer componente que explicó el 48,37\% del total.
Las variables climáticas con mayor correlación de factores, fueron las temperaturas mínima y media (Tmín y Tmed).

El coeficiente de correlación obtenido del análisis de regresión múltiple $(\mathrm{r}=0,82)$ y el valor de $\mathrm{P}$ del ANOVA $(0,0000)$, indicó que existió relación estadística significativa entre las variables temperatura y brix de la hoja, con un nivel de confidencia del $95 \%$. El estadístico R2 indica que el modelo así ajustado explica $67,24 \%$ de la variabilidad del brix de la hoja (BrixH), como expresión de los síntomas de la enfermedad. La ecuación obtenida fue la siguiente: $\mathrm{BrixH}=$ $-5,56753-3,14193 *$ Tmin $+3,14718 *$ Tmed.

Cuadro 3. Resultado de los análisis de componentes principales de los datos obtenidos en planta de caña de azúcar, bajo la incidencia del amarillamiento de la hoja (SCYP). Cienfuegos 2003-2005 y Villa Clara 2004-2006. Cuba.

\begin{tabular}{lcc}
\hline Análisis de Componentes Principales & Componente 1 & Componente 2 \\
\hline Valores propios & 3,8695 & 1,7893 \\
\% Total de la varianza & 48,3690 & 22,3674 \\
Valor acumulado & 3,8695 & 5,6589 \\
\% Total de la varianza acumulada & 48,3690 & 70,7364 \\
Correlación de Factores & Factor 1 & Factor 2 \\
Temperatura máxima media (Tmax) (Co) & $-0,8776$ & $-0,3067$ \\
Temperatura mínima media (Tmin) (Co) & $-0,9771$ & $-0,0868$ \\
Temperatura media (Tmed) (Co) & $-0,9546$ & $-0,1836$ \\
Humedad relativa (HR) (\%) & $-0,5852$ & 0,5728 \\
Evaporación (Evap) (mm) & 0,0039 & $-0,9013$ \\
Precipitación (Prec) (mm) & $-0,5672$ & 0,1531 \\
Brix de la hoja (BrixH) & 0,7488 & $-0,2187$ \\
Edad (días) & 0,0903 & 0,6648 \\
\hline
\end{tabular}


Existió una relación inversa entre las temperaturas mínima y media con el brix de la hoja. Las mínimas y medias inferiores a 19 y $25^{\circ} \mathrm{C}$, respectivamente, favorecieron la expresión de los síntomas en caña planta, independientemente del ciclo de plantación (Primavera y Frío) (Figuras 3 y 4).

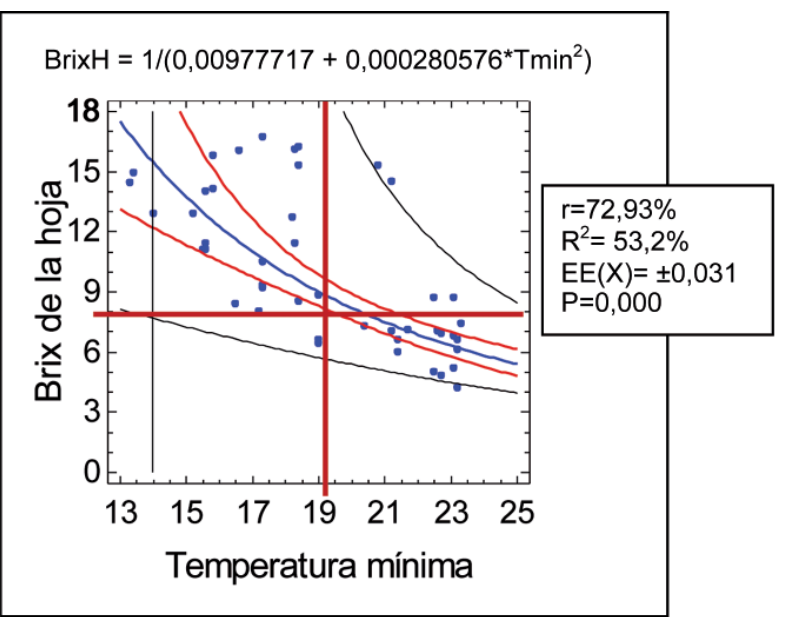

Figura 3. Relación entre el brix de la hoja y la temperatura mínima de caña de azúcar bajo la incidencia de amarillamiento de la hoja (SCYP). Cienfuegos 2003-2005 y Villa Clara 2004-2006, Cuba.
Como resultado del análisis de componentes principales, en la cepa de retoño (Cuadro 4), dos explicaron el $89,29 \%$ del total de la varianza y fue más importante el primer componente que explicó el 68,47\% del total de la varianza. Las variables climáticas de temperatura (máxima, mínima y media) y la precipitación,

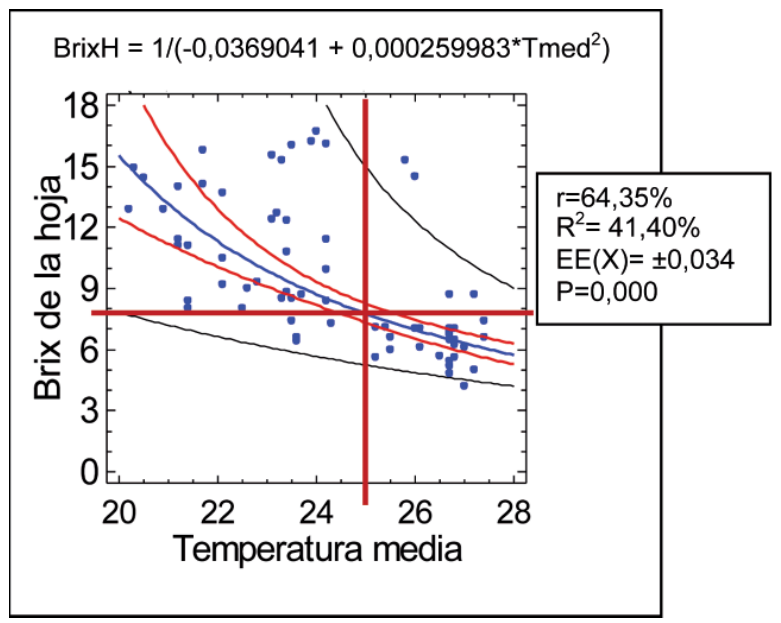

Figura 4. Relación entre el brix de la hoja y la Temperatura media en caña de azúcar bajo la incidencia de amarillamiento de la hoja (SCYP). Cienfuegos 2003-2005 y Villa Clara 2004-2006. Cuba.

Cuadro 4. Resultado de los análisis de componentes principales de los datos obtenidos en cepa de retoño de caña de azúcar bajo la incidencia de amarillamiento de la hoja (SCYP). Cienfuegos 2006 y Villa Clara 2007, Cuba.

\begin{tabular}{lcc}
\hline Análisis de Componentes Principales & Componente 1 & Componente 2 \\
\hline Valores propios & 5,4781 & 1,2655 \\
\% Total de la varianza & 68,4773 & 15,8194 \\
Valor acumulado & 5,4781 & 6,74374 \\
\% Total de la varianza acumulada & 68,4770 & 84,2968 \\
Correlación de factores & Factor 1 & Factor 2 \\
Temperatura máxima media (Tmax) (Co) & 0,934450 & 0,180533 \\
Temperatura mínima media (Tmin) (Co) & 0,921375 & $-0,108888$ \\
Temperatura media (Tmed) (Co) & 0,975551 & 0,052086 \\
Humedad relativa (HR) (\%) & 0,440851 & $-0,853800$ \\
Evaporación (Evap) (mm) & 0,674031 & 0,588298 \\
Precipitación (Prec) (mm) & 0,820953 & $-0,173791$ \\
Brix de la hoja (BrixH) & $-0,841451$ & 0,241119 \\
Edad (días) & $-0,879597$ & $-0,234480$ \\
\hline
\end{tabular}


conjuntamente con la edad de las plantas después de la cosecha, mostraron la mayor correlación de factores.

El coeficiente de correlación obtenido del análisis de regresión múltiple $(\mathrm{r}=0,89)$ y el valor de $\mathrm{P}$ del ANOVA $(0,0000)$, indicó que existió una relación estadística significativa entre las variables de mayor factor de correlación y el brix de la hoja, con un nivel de confidencia del $95 \%$. El estadístico $\mathrm{R}^{2}$ indica que el modelo así ajustado explica $80,68 \%$ de la variabilidad del brix de la hoja. La ecuación obtenida fue la siguiente:

BrixH $=-27,116+1,192 * \mathrm{Tmax}-0,557 * \mathrm{Tmin}+0,1762$ *Tmed-0,02156*Prec+ 0,03152*Edad'

Estos resultados mostraron además, que a diferencia de los resultados estadísticos obtenidos en caña planta, en retoño existió una relación significativa entre la edad de las plantaciones y el brix de la hoja.

En la cepa de retoño, existió una relación inversa entre las temperaturas máxima, mínima y media con el brix de la hoja. Las temperaturas máximas, mínimas y medias inferiores a 30,21 y $25^{\circ} \mathrm{C}$, respectivamente, favorecieron la expresión de los síntomas en la cepa de retoño (Figuras 5, 6 y 7). De igual manera, las precipitaciones mensuales inferiores a $50 \mathrm{~mm}$, favorecieron también el incremento del brix de la hoja (Figura 8).

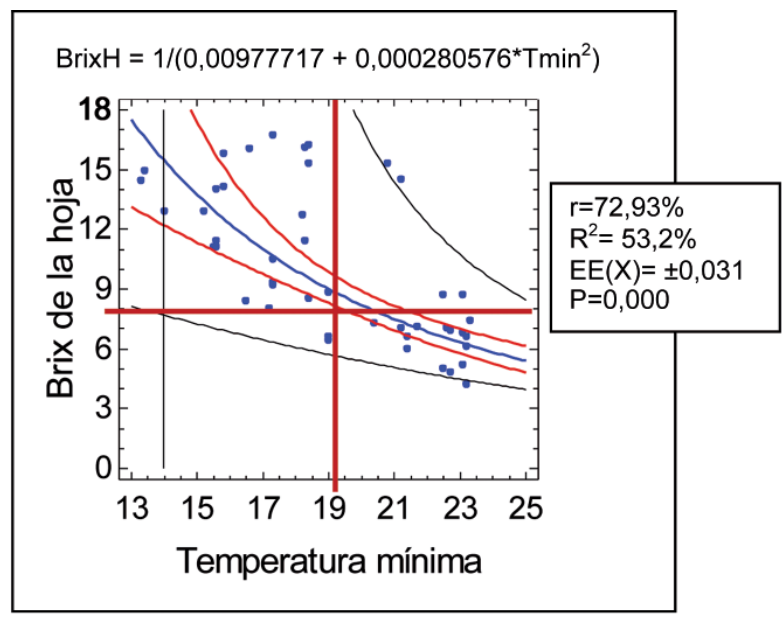

Figura 5. Relación entre el brix de la hoja y la temperatura máxima en cepa de retoño de caña de azúcar en pesencia del amarillamiento de la hoja (SCYP). Cienfuegos 2006 y Villa Clara 2007, Cuba.
Con el incremento de la edad de las plantas, posterior a los siete meses de edad (221 días), se incrementaron los valores de brix de la hoja, llegando a valores superiores a 14 en el momento próximo a la cosecha con edad de doce meses (260 días) (Figura 9). De acuerdo con Fitch et al. (2001), la expresión de los síntomas de SCYLV puede estar influenciada por las condiciones

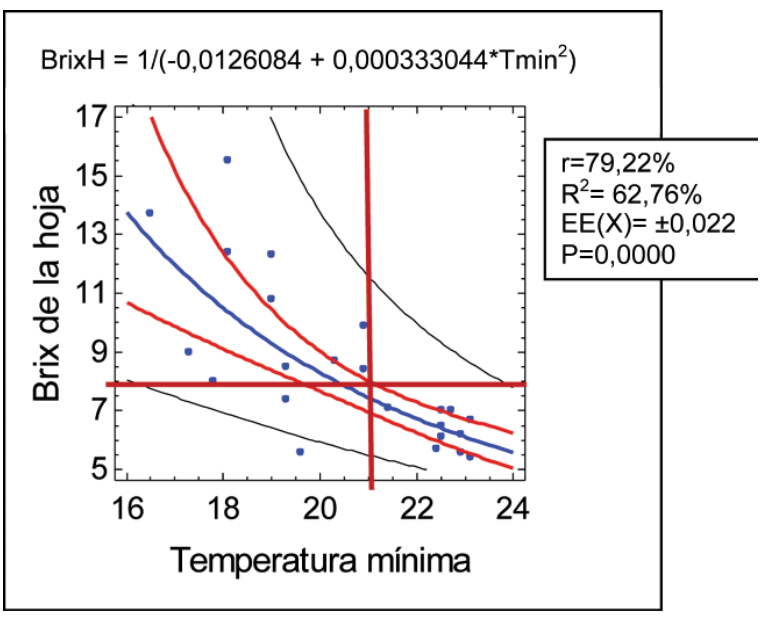

Figura 6. Relación entre el brix de la hoja y la temperatura mínima en cepa de retoño de caña de azúcar en pesencia del amarillamiento de la hoja (SCYP). Cienfuegos 2006 y Villa Clara 2007, Cuba.

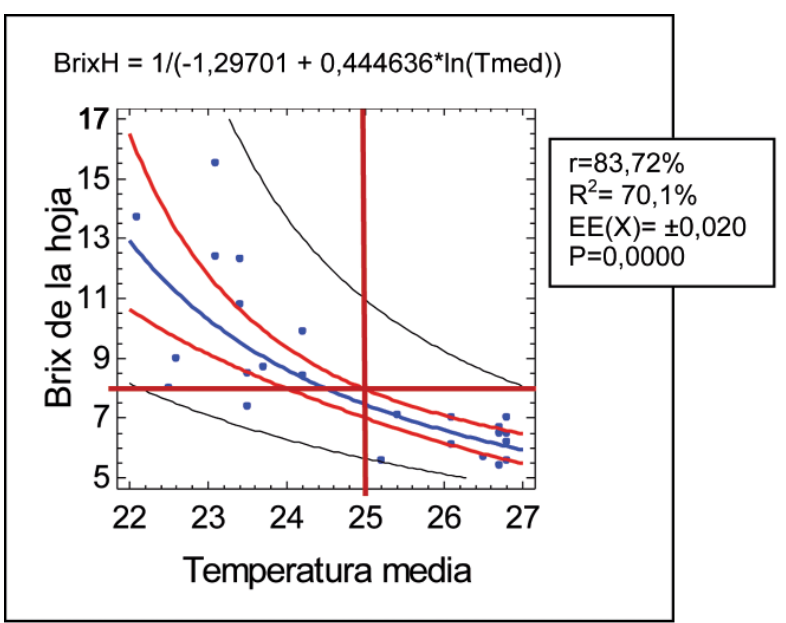

Figura 7. Relación entre el brix de la hoja y la temperatura media en cepa de retoño de caña de azúcar en pesencia del amarillamiento de la hoja (SCYP). Cienfuegos 2006 y Villa Clara 2007, Cuba. 


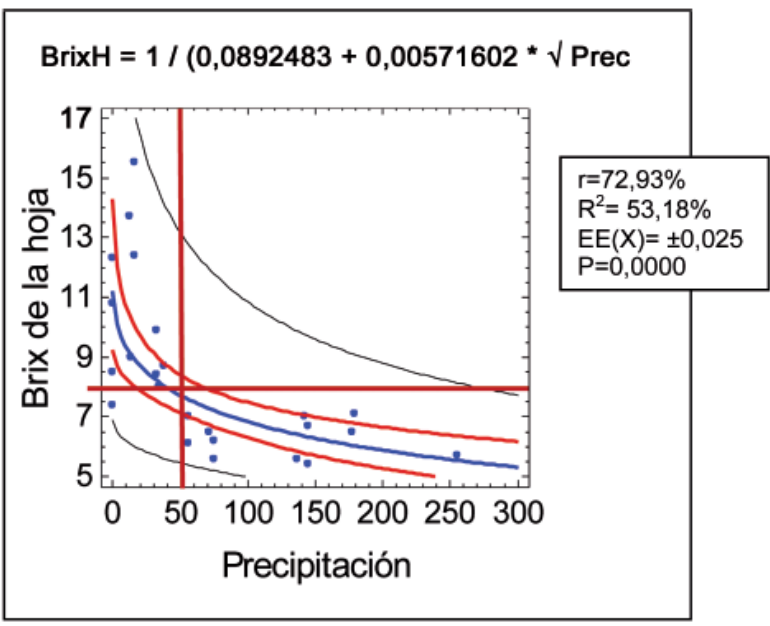

Figura 8. Relación entre el brix de la hoja y la precipitación en cepa de retoño de caña de azúcar bajo la incidencia del amarillamiento de la hoja (SCYP). Cienfuegos 2006 y Villa Clara 2007, Cuba.

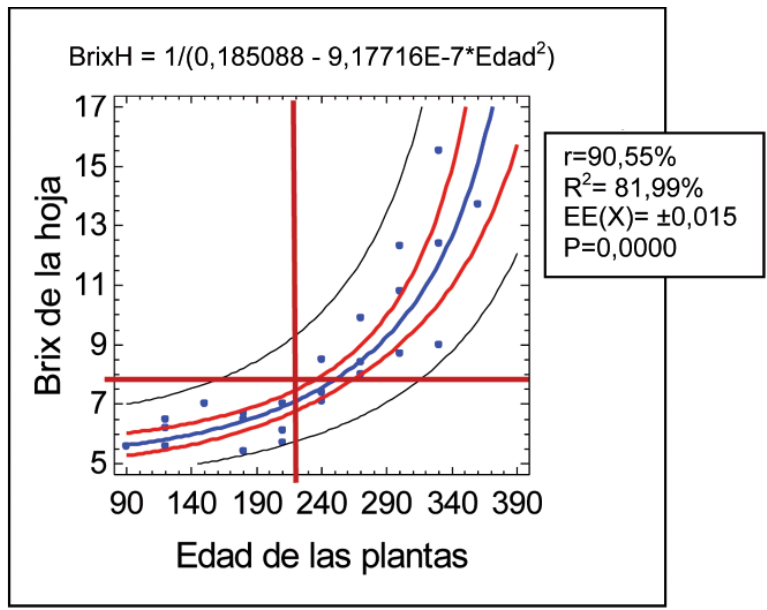

Figura 9. Relación entre el brix de la hoja y la edad de las plantas en cepa de retoño de caña de azúcar bajo la incidencia del amarillamiento de la hoja (SCYP). Cienfuegos 2006 y Villa Clara 2007, Cuba.

del medio ambiente, tales como disponibilidad de agua y temperatura del aire, los resultados obtenidos en el presente estudio muestran que algo similar ocurre en el caso del SCYP. Resultados similares fueron obtenidos en Venezuela por Figueredo et al. (2004), ellos determinaron que el aumento de la incidencia del SCYLV coincide con el período poco lluvioso del año y la etapa de floración-maduración de la caña. McAllister et al. (2006), indican que el gran período de incremento de SCYLV en Luisiana (EE.UU), ocurre durante el final de la primavera y comienzos del verano.

Los resultados de este estudio, corroboraron la presencia del amarillamiento de la hoja (SCYP) en la región central de Cuba y mostraron que los primeros síntomas fisiológicos típicos, aparecieron en muestras foliares de caña de azúcar a partir de los cinco meses de edad, independientemente de la época de plantación. Los síntomas se manifestaron con el inicio de la estación invernal y disminuyeron con el inicio de la primavera. El brix de la hoja se incrementó desde noviembre y alcanzó un máximo en el mes de abril, posteriormente las plantas se tornaron asintomáticas. La disminución de las temperaturas máximas, mínimas y medias inferiores a 30,21 y $25^{\circ} \mathrm{C}$, respectivamente, así como precipitaciones mensuales inferiores a $50 \mathrm{~mm}$, favorecieron la expresión de los síntomas.

La presencia de los síntomas fisiológicos de la enfermedad en cepa de caña planta, estuvieron más relacionados con el clima que con la edad del cultivo, mientras que en retoño, en la medida que se aproxima la edad y época de cosecha óptima, se incrementaron los síntomas, debido fundamentalmente a las condiciones climáticas y coincidentemente con el período seco (diciembre hasta abril) y de maduración de la caña de azúcar en Cuba.

\section{LITERATURA CITADA}

Arocha, Y; González, L; Peralta, EL; Jones, P. 1999. First report of virus and phytoplasma pathogens associated whit yellow leaf syndrome of sugarcane in Cuba. Plant Disease 83:1177.

Arocha, Y; Jones, P; Sumac, I; Peralta, EL. 2000. Detección de fitoplasmas asociados al síndrome de la hoja amarilla en Cuba. Revista de Protección Vegetal 15:81-87.

Arocha, Y; Peralta EL; Jones P. 2004. Validación del sistema de diagnóstico molecular de fitoplasmas asociados con el síndrome del amarillamiento foliar de la caña de azúcar (YLS) en Cuba y su comparación con el método de campo. Revista Protección Vegetal 19(1):19-25. Arocha, Y; Almeida, R; Peralta, EL; Carbajal, O; Jones, P. 2005. Update data on distribution of yellow leaf síndrome (YLS) in Cuba. Revista Protección Vegetal 20(2):1-5. 
Arocha,Y; Piñol, B; Peralta, EL; Almeida, R; Picornell, B; Jones, P. 2006. Biodiversidad y distribución de los fitoplasmas asociados con el síndrome del amarillamiento foliar (YLS) en Cuba. Revista Fitosanidad 21(1):8-15.

Ávila, R; Arrieta, MC; Villalobos, W; Moreira, L; Lockhart, BEL; Riera, C. 2001. First report of sugarcane yellow leaf virus (ScYLV) in Costa Rica. Plant Disease 85:919.

Bailey, R; Bechet, G; Cronjé, P. 1996. Notes on the occurrence of yellow leaf syndrome of sugarcane in southern Africa. Proceedings South African Sugar Technologists Association 70:3-6.

Comstock, J; Irey, M; Lockhart B; Wang, Z. 1998. Incidence of yellow leaf syndrome in CP cultivars based on polymerase chain reaction and serological techniques. Sugar Cane 4:21-24.

Cronjé, CPR; Wesley-Smith, J; Maartens, P. 1996.Yellow leaf syndrome of sugarcane: the search for a causal agent. Microscopy Society of Southern Africa, Proceedings 26:45-49.

Cronjé, P; Tymon, A; Jones, P; Bailey, R. 1998. Association of a phytoplasma with a yellow leaf syndrome of sugarcane in Africa. Ann. Appl. Biology 133:77-186.

Figueredo, L; Hernández, L; Linares, B. 2004. Relación epidemiológica entre áfidos (Homoptera: Afididae) y enfermedades virales en el cultivo de la caña de azúcar en los valles de los ríos Turbio y Yaracuy, Venezuela. Rev. Caña de Azúcar 22(1):15-19.

Fitch, MMM; Lehrer, AT; Komor, E; Moore, P.H. 2001. Elimination of sugarcane yellow leaf virus from infected sugarcane plants by meristem tip culture visualized by tissue blot immunoassay. Plant Pathology 50:676-680.

Fontaniella, B; Vicente, C; Legaz, ME; Armas, R; Rodríguez CW; Martínez, M; Piñón, D; Acevedo, R; Salas, MT. 2003. Yellow leaf syndrome modifies the composition of sugarcane juices in polysaccharides, phenols and polyaminas. Plant Physiology and Biochemistry 41:1027-1036.

Garces, FF; Balladarez, C; Quiridumbay, G; Muñoz, C. 2005. Diagnosis of leaf fleck, leaf scald, mosaic, ratoon stunting disease in commercial fields and quarantine in Ecuador. Proceedings International Society Sugar Cane Technologists 25:695-700.
Hernández, A; Pérez, JM; Bosch, D; Rivero, L. 1999. Nueva versión de clasificación genética de los suelos de Cuba. Edit. AGRINFOR, Ciudad Habana. 64 p.

Lockhart, BE; Cronjé, CPR. 2000. Yelow leaf syndrome. p. 291-295. In Rott, P; Bailey, RA; Constuck, JC; Croft, BJ; Sauntally, AS. eds. A guide to sugarcane diseases. Editions Répères, Centre do cooperation internationals en recherché agronomique pour le development (CIRAD) and International Society of Sugar Cane Technologists (ISSCT) Montpellier, France. 339 p.

McAllister, CD; Hoy, JW; Reagan, TE. 2006. Temporal increase and spatial distribution of yellow leaf and sugarcane aphid infestations. In Programme and abstracts of the VIII th ISSCT Pathology Worshop Petit-Bourg, Guadeloupe (FWI), 23-27, January 2006. sp.

Parmessur, Y; Aljanabi, S; Saumtally, S; Dookun-Sauntally, A. 2002. Sugarcane yellow leaf virus and sugarcane yellows phytoplasma: elimination by tissue culture. Plant Pathology 51:561-566.

Peralta, EL; Chinea, A; Arocha, Y; Piñón, D. 1999. Informe proyecto CITMA III-033. Estudio, diagnóstico y control del Síndrome de Amarillamiento Foliar de la Caña de Azúcar (YLS) en Cuba, Cuba, INICA. 150 p.

Rott, P; Comstock, JC; Croft, BJ; Kusalwong, A; Saumtally, SA. 2005. Advances and challenges in sugarcane pathology. Proceedings International Society Sugar Cane Technologists 25:607-614.

Rott, P; Mirkov TE; Schenck, S; Girard, JC. 2008. Recent advances in research on sugarcane yellow leaf virus, the causal agent of sugarcane yellow leaf. Sugar Cane International 26(3):18-22.

Schenck, S. 1990. Report on the hawaiian sugar planter association experiment station for 1990. p. 38.

Schenck, S; Hu, J. 1991. Update on the cause of sugarcane yellow leaf syndrome. Proceedings Hawaiian Sugar Technologists Association 50:45-46.

Schenck, S; Hu, J; Lockhart, B. 1997. Use of a tissue blot immunoassay to determine the distribution of sugarcane yellow leaf virus in Hawaii. Sugar Cane 4:5-8.

Smith, GR; Braithwaite, KS; Cronje, CPR. 2001. The viral and phytoplasma forms of yellow leaf syndrome of sugarcane. International Society Cane Technologits Proceedings of the XXIV Congress, Brisbane, Australia 2:614-617.

Soil Survey Staff. 2003. Keys to soil taxonomy. USDA, 9 ed. 332 p. 